Ever-sporting varieties may be illustrated by such races as the five-leaved clover of de Vries and his fasciated teasel. The theory of mutation can not be better illustrated than by the classical example of Lamarck's evening primrose with some of its most striking mutants.

Hybridization, as one of the most important means of effecting changes in combination of plant characters, demands a prominent consideration in the section of the garden under discussion. Mendel's law can perhaps best be shown by hybrids between white- and scarlet-flowered races of a freeblooming species like the scarlet runner bean in which the color characters are evident in vegetative as well as in floral parts, and the assumption of color factors is not necessary to explain the color relations of the offspring. If suitable examples can be obtained, blend and mosaic hybrids might also be illustrated.

Due to hybridization and other causes, the sexually formed seed can not be depended upon to reproduce the characters of the parents without change. Vegetative means of reproduction such as cuttings, since they merely increase the individual plant, do, however, reproduce individual characters. Sowings from seeds and roots respectively, from a single plant of some modern type of dahlia would show the truth of the saying, that cuttings come true, but seedlings do not.

It has been the writer's practise to have each student choose some single plant for personal investigation to find out from the plant itself as much as possible without unfavorable prejudice from literature. The amount of work has been largely voluntary and a reasonable proportion of the students have responded to the suggestions offered them for this elementary research work. A portion of the garden is reserved for carrying out cultures and experiments, which the students themselves may suggest, in connection with their plants under investigation.

The special type of botanic garden which has thus been outlined by specific examples is the outgrowth of the needs of a teaching botanist in an agricultural institution. It has furnished material for demonstration purposes, for laboratory exercises and for field observations. Its systematic section being built on the plan of the pocket dictionary with the most used forms represented has been considered as forming a not unnatural basis of a student's list of recognizable plants, and accordingly ability to identify the species grown in the garden has been expected of students taking botany.

Though the chief function of the agricultural botanic garden may be considered as being instructional for special courses, it should prove of interest to students outside their classes and to a visiting public. It may, therefore, be not inappropriately termed a field museum of agriculture.

\section{A. F. Blakeslee}

THE PSYCHOLOGY OF SOCIAL CONSCIOUSNESS IMPLIED IN INSTRUCTION ${ }^{1}$

I HAVE been asked to present the social situation in the school as the subject of a possible scientific study and control.

The same situation among primitive people is scientifically studied by the sociologist (folk-psychologist). $\mathrm{He}$ notes two methods in the process of primitive education. The first is generally described as that of play and imitation. The impulses of the children find their expression in play, and play describes the attitude of the child's consciousness. Imitation defines the form of unconscious social control

\footnotetext{
${ }^{1}$ Read before Section L-Education. American Association for the Advancement of Science, Boston, December, 1909.
} 
exercised by the community over the expression of childish impulse.

In the long ceremonies of initiation education assumed a more conscious and almost deliberate form. The boy was induced into the clan mysteries, into the mythology and social procedure of the community, under an emotional tension which was skilfully aroused and maintained. He was subjected to tests of endurance which were calculated not only to fulfil this purpose, but also to identify the ends and interests of the individual with those of the social group. These more general purposes of the initiatory ceremonies were also at times cunningly adapted to enhance the authority of the medicine man or the control over food and women by the older men in the community,

Whatever opinion one may hold of the interpretation which folk-psychology and anthropology have given of this early phase of education, no one would deny, I imagine, the possibility of studying the education of the savage child scientifically, nor that this would be a psychological study. Imitation, play, emotional tensions favoring the acquirement of clan myths and cults, and the formation of clan judgments of evaluation, these must be all interpreted and formulated by some form of psychology. The particular form which has dealt with these phenomena and processes is social psychology. The important features of the situation would be found not in the structure of the idea to be assimilated considered as material of instruction for any child, nor in the lines of association which would guarantee their abiding in consciousness. They would be found in the impulse of the children expressed in play, in the tendency of the children to put themselves in the place of the men and women of the group, $i$. e., to imitate them in the emotions which con- sciousness of themselves in their relationship to others evoke, and in the import for the boy which the ideas and cults would have when surcharged with such emotions.

If we turn to our system of education we find that the materials of the curriculum have been presented as percepts capable of being assimilated by the nature of their content to other contents in consciousness, and the manner has been indicated in which this material can be most favorably prepared for such assimilation. This type of psychological treatment of material and the lesson is recognized at once as Herbartian. It is an associational type of psychology. Its critics add that it is intellectualistic. In any case it is not a social psychology, for the child is not primarily considered as a self among other selves, but as an apperceptionsmasse. The child's relations to the other members of the group, to which he belongs, have no immediate bearing on the material nor on the learning of it. The banishment from the traditional school work of play and of any adult activities in which the child could have a part as a child, $i$. e., the banishment of processes in which the child can be conscious of himself in relation to others, means that the process of learning has as little social content as possible.

An explanation of the different attitudes in the training of the child in the primitive and in the modern civilized communities is found, in part, in the division of labor between the school on the one side, and the home and the shop or the farm on the other. The business of storing the mind with ideas, both materials and methods, has been assigned to the school. The task of organizing and socializing the self to which these materials and methods belong is left to the home and the industry or profession, to the playground, the 
street and society in general. A great deal of modern educational literature turns upon the fallacy of this division of labor. The earlier vogue of manual training and the domestic arts before the frank recognition of their relation to industrial training took place, was due in no small part to the attempt to introduce those interests of the child's into the field of his instruction which gathers about a socially constituted self, to admit the child's personality as a whole into the school.

I think we should be prepared to admit the implication of this educational movement-that however abstract the material is which is presented and however abstracted its ultimate use is from the immediate activities of the child, the situation implied in instruction and in the psychology of that instruction is a social situation; that it is impossible to fully interpret or control the process of instruction without recognizing the child as a self and viewing his conscious processes from the point of view of their relation in his consciousness to his self, among other selves.

In the first place, back of all instruction lies the relation of the child to the teacher and about it lie the relations of the child to the other children in the school-room and on the play-ground. It is, however, of interest to note that so far as the material of instruction is concerned an ideal situation has been conceived to be one in which the personality of the teacher disappears as completely as possible behind the process of learning. In the actual process of instruction the emphasis upon the relation of pupil and teacher in the consciousness of the child has been felt to be unfortunate. In like manner the instinctive social relations between the children in school hours is repressed. In the process of memorizing and reciting a lesson, or working out a problem in arithmetic a vivid consciousness of the personality of the teacher in his relationship to that of the child would imply either that the teacher was obliged to exercise discipline to carry on the process of instruction, and this must in the nature of the case constitute friction and division of attention, or else that the child's interest is distracted from the subject matter of the lesson, to something in which the personality of the teacher and pupil might find some other content; for even a teacher's approval and a child's delight therein has no essential relation to the mere subject matter of arithmetic or English. It certainly has no such relationship as that implied in apprenticeship, in the boy's helping on the farm or the girl's helping in the housekeeping, has no such relationship as that of members of an athletic team to each other. In these latter instances the vivid consciousness of the self of the child and of his master, of the parents whom he helps and of the associates with whom he plays is part of the child's consciousness of what he is doing, and his consciousness of these personal relationships involves no division of attention. Now it had been a part of the fallacy of an intellectualistic pedagogy that a divided attention was necessary to insure application of attention-that the rewards, and especially the punishments, of the school hung before the child's mind to catch the attention that was wandering from the task, and through their associations with the schoolwork to bring it back to the task. This involves a continual vibration of attention on the part of the average child between the task and the sanctions of school discipline. It is only the psychology of school discipline that is social. The pains and penalties, the pleasures of success in competition, of favorable 
mention of all sorts implies vivid self-consciousness. It is evident that advantage would follow from making the consciousness of self or selves which is the life of the child's play-on its competition or cooperation-have as essential a place in instruction. To use Professor Dewey's phrase, instruction should be an interchange of experience in which the child brings his experience to be interpreted by the experience of the parent or teacher. This recognizes that education is interchange of ideas, is conversation-belongs to a universe of discourse. If the lesson is simply set for the child-is not his own problemthe recognition of himself as facing a task and a task-master is no part of the solution of the problem. But a difficulty which the child feels and brings to his parent or teacher for solution is helped on toward interpretation by the consciousness of the child's relation to his pastors and masters. Just in so far as the subject matter of instruction can be brought into the form of problems arising in the experience of the child-just so far will the relation of the child to the instructor become a part of the natural solution of the problem-actual success of a teacher depends in large measure upon this capacity to state the subject matter of instruction in terms of the experience of the children. The recognition of the value of industrial and vocational training comes back at once to this, that what the child has to learn is what he wants to acquire, to become the man. Under these conditions instruction takes on frankly the form of conversation, as much sought by the pupil as the instructor.

I take it therefore to be a scientific task to which education should set itself that of making the subject matter of its instruction the material of personal intercourse between pupils and instructors, and between the children themselves. The sub- stitution of the converse of concrete individuals for the pale abstractions of thought.

To a large extent our school organization reserves the use of the personal relation between teacher and taught for the negative side, for the prohibitions. The lack of interest in the personal content of the lesson is in fact startling when one considers that it is the personal form in which the instruction should be given. The best illustration of this lack of interest we find in the problems which disgrace our arithmetics. They are supposed matters of converse, but their content is so bare, their abstractions so raggedly covered with the form of questions about such marketing and shopping and building as never were on sea or land, that one sees that the social form of instruction is a form only for the writer of the arithmetic. When further we consider how utterly inadequate the teaching force of our public schools is to transform this matter into concrete experience of the children or even into their own experience, the hopelessness of the situation is overwhelming. Ostwald has written a text-book of chemistry for the secondary school which has done what every textbook should do. It is not only that the material shows real respect for the intelligence of the student, but it is so organized that the development of the subject matter is in reality the action and reaction of one mind upon another mind. The dictum of the Platonic Socrates, that one must follow the argument where it leads in the dialogue, should be the motto of the writer of text-books.

It has been indicated already that language being essentially social in its nature thinking with the child is rendered concrete by taking on the form of conversation. It has been also indicated that this can take place only when the thought has reference to a real problem in the experi- 
ence of the child. The further demand for control over attention carries us back to the conditions of attention. Here again we find that traditional school practise depends upon social consciousness for bringing the wandering attention back to the task, when it finds that the subjective conditions of attention to the material of instruction are lacking, and even attempts to carry over a formal self-consciousness into attention, when through the sense of duty the pupil is called upon to identify the solution of the problem with himself. On the other hand, we have in vocational instruction the situation in which the student has identified his impulses with the subject matter of the task. In the former case, as in the case of instruction, our traditional practise makes use of the selfconsciousness of the child in its least effective form. The material of the lesson is not identified with the impulses of the child. The attention is not due to the organization of impulses to outgoing activity. The organization of typical school attention is that of a school self, expressing subordination to school authority and identity of conduct with that of all the other children in the room. It is largely inhibitive-a consciousness of what one must not do, but the inhibitions do not arise out of the consciousness of what one is doing. It is the nature of school attention to abstract from the content of any specific task. The child must give attention first and then undertake any task which is assigned him, while normal attention is essentially selective and depends for its inhibitions upon the specific act.

Now consciousness of self should follow upon that of attention, and consists in a reference of the act, which attention has mediated, to the social self. It brings about a conscious organization of this particular act with the individual as a whole
- makes it his act, and can only be effectively accomplished when the attention is an actual organization of impulses seeking expression. The separation between the self, implied in typical school attention, and the content of the school tasks, makes such an organization difficult if not impossible.

In a word attention is a process of organization of consciousness. It results in the reenforcement and inhibitions of perceptions and ideas. It is always a part of an act and involves the relation of that act to the whole field of consciousness. This relation to the whole field of consciousness finds its expression in consciousness of self. But the consciousness of self depends primarily upon social relations. The self arises in consciousness pari passu with the recognition and definition of other selves. It is therefore unfruitful if not impossible to attempt to scientifically control the attention of children in their formal education, unless they are regarded as social beings in dealing with the very material of instruction. It is this essentially social character of attention which gives its peculiar grip to vocational training. From the psychological point of view, not only the method and material but also the means of holding the pupils' attention must be socialized.

Finally a word may be added with reference to the evaluations-the emotional reactions-which our education should call forth. There is no phase of our public school training that is so defective as this. The school undertakes to acquaint the child with the ideas and methods which he is to use as a man. Shut up in the history, the geography, the language and the number of our curricula should be the values that the country, and its human institutions, have; that beauty has in nature and 
art; and the values involved in the control over nature and social conditions.

The child in entering into his heritage of ideas and methods should have the emotional response which the boy has in a primitive community when he has been initiated into the mysteries and the social code of the group of which he has become a citizen. We have a few remainders of this emotional response, in the confirmation or conversion and entrance into the church, in the initiation into the fraternity, and in the passage from apprenticeship into the union. But the complexities of our social life, and the abstract intellectual character of the ideas which society uses have made it increasingly difficult to identify the attainment of the equipment of a man with the meaning of manhood and citizenship.

Conventional ceremonies at the end of the period of education will never accomplish this. And we have to further recognize that our education extends for many far beyond the adolescent period to which this emotional response naturally belongs. What our schools can give must be given through the social consciousness of the child as that consciousness develops. It is only as the child recognizes a social import in what he is learning and doing that moral education can be given.

I have sought to indicate that the process of schooling in its barest form can not be successfully studied by a scientific psychology unless that psychology is social, $i$. e., unless it recognizes that the processes of acquiring knowledge, of giving attention, of evaluating in emotional terms must be studied in their relation to selves in a social consciousness. So far as education is concerned, the child does not become social by learning. He must be social in order to learn.

Geo. H. MEAD

The University of Chicago
STATISTICS OF FOREIGN UNIVERSITIES

THE accompanying table shows the enrollment during the winter semester (1909-10) at the universities of the German Empire, at all of the Swiss universities except Neuchâtel, and at several of the Austrian and Hungarian universities, the figures having been furnished in each instance by an officer of the institution concerned. The division into the four traditional faculties of theology, law, medicine and philosophy has been adhered to, no attempt being made to subdivide the last mentioned faculty into the two groups - (a) philosophy, philology and history, (b) mathematics and the natural sciences - represented at most of the institutions in the list. Nor has any attempt been made to provide special categories for dentistry, pharmacy, forestry, agriculture, etc., the custom being to include dentistry under medicine (or philosophy) and the other subjects under philosophy.

It will be seen from the table that 58,342 students were in attendance at the German universities, 93.5 per cent. of these being men and 6.5 per cent. women. The matriculated students constituted 90.8 per cent. of the grand total and the auditors 9.2 per cent. Of the matriculated students 96.5 per cent. were men and only 3.5 per cent. women, there being practically no women enrolled in theology and only a few in law, the great majority being found in philosophy. Of the auditors, on the other hand, no less than 36.3 per cent. were women-Göttingen, Greifswald, Königsberg, Marburg, Rostock, Strassburg and Würzburg all having more female than male auditors. Almost one half (49.4 per cent.) of the matriculated students are enrolled in the faculty of philosophy, law coming next with 21.9 per cent., then medicine with 21.1 per cent., and finally theology with 7.6 per cent. 